\title{
Trauma Surgery \& Acute Care Open \\ Characterization of organ dysfunction and mortality in pediatric patients with trauma with acute traumatic coagulopathy
}

\author{
Alison Nair, ${ }^{1}$ Heidi Flori, ${ }^{2}$ Mitchell Jay Cohen ${ }^{3}$
}

\begin{abstract}
'Department of Pediatrics, University of California San Francisco, San Francisco, California, USA

2Department of Pediatrics, University of Michigan, Ann Arbor, Michigan, USA ${ }^{3}$ Denver Health and Hospital Authority, Denver, Colorado, USA
\end{abstract}

\section{Correspondence to} Dr Alison Nair, Pediatrics, University of California San Francisco, San Francisco, California 94158, USA; Alison. Nair@ucsf.edu

Received 12 September 2019 Revised 5 November 2019 Accepted 11 November 2019 (c) Author(s) (or their employer(s)) 2019. Re-use permitted under CC BY-NC. No commercial re-use. See rights and permissions. Published by BMJ.

To cite: Nair A, Flori $\mathrm{H}_{\text {, }}$ Cohen MJ. Trauma Surg Acute Care Open 2020;5:e000382.

\begin{abstract}
Background Traumatic injuries are a leading cause of mortality and morbidity in pediatric patients and abnormalities in hemostasis play an important role in these poor outcomes. One such abnormality, acute traumatic coagulopathy (ATC), is a near immediate endogenous response to injury and has recently been described in the pediatric population. This study aims to evaluate the epidemiology of pediatric ATC, specifically its association with organ dysfunction.

Methods All patients with trauma presenting to the University of California, Benioff Children's Hospital Oakland between 2006 and 2015 with coagulation testing drawn at presentation were included. Patients were excluded if they (1) were $>18$ years of age, (2) were admitted with a non-mechanical mechanism of injury, (3) were on anticoagulation medications, or (4) had coagulation testing $>4$ hours after injury. ATC was defined as an international normalized ratio (INR) $\geq 1.3$. The primary outcome was new or progressive multiple organ dysfunction syndrome (MODS) and secondary outcomes included in-hospital mortality and other morbidities.
\end{abstract}

Results Of the 7382 patients that presented in the 10year study period, 545 patients met criteria for analysis and 88 patients $(16 \%)$ presented with ATC. Patients with ATC were more likely to develop MODS than those without ATC $(68.4 \%$ vs $7.7 \%, p<0.001)$ and had higher in-hospital mortality $(26.1 \%$ vs $0.4 \%, p<0.001)$ than those without ATC. Along with arterial hypotension and an Injury Severity Score $\geq 30$, ATC was independent predictor of MODS and in-hospital mortality. An isolated elevated INR was associated with MODS and in-hospital mortality while an isolated elevated partial thromboplastin time was not.

Conclusions Pediatric ATC was associated with organ dysfunction, mortality, and other morbidities. ATC along with arterial hypotension and high injury severity were independent predictors of organ dysfunction and mortality. Pediatric ATC may be biologically distinct from adult ATC and further studies are needed.

Level of evidence IV, epidemiologic.

\section{BACKGROUND}

Traumatic injuries are the leading cause of mortality in children and young adults, accounting for more than $45 \%$ of all deaths in patients 1-19 years of age in the USA. ${ }^{1-4}$ Furthermore, ongoing disability following non-fatal traumatic injury affects approximately $50 \%$ of pediatric patients..$^{5-7}$ Due to hospital and long-term care expenses, the economic costs of pediatric trauma have been estimated at $\$ 14$ billion in lifetime medical spending and \$66billion in present and future work loss. ${ }^{8-10}$ Despite its impact on outcomes, there is much to learn about the pathophysiological processes and clinical constellations that drive mortality and morbidity following pediatric injury.

In adults, trauma-induced coagulopathy (TIC) seems to play a critical role in outcomes following trauma. Historically, all TIC was thought to be related to patient management. Now termed iatrogenic coagulopathy, this type of coagulopathy has been attributed to (1) dilution of coagulation factors after crystalloid and red blood cell resuscitation, (2) blood loss and consumption due to ongoing bleeding and procedures, (3) hypothermia from exposure and infusion of unwarmed resuscitation fluids, and (4) resultant acidosis. ${ }^{11}$ Sixteen years ago, a distinct group of adult patients with trauma was described that present with coagulopathy prior to these exposures and interventions. ${ }^{12}$ This early coagulopathy, referred to as either early TIC or acute traumatic coagulopathy (ATC), is an endogenous biologic response that occurs nearly immediately after injury and is independent of iatrogenic causes of dysfunctional hemostasis. ${ }^{13}$ ATC is thought to be part of a pathway in which traumatic injury triggers a combination of mechanical tissue trauma, oxygen debt, and inflammation, which impairs coagulation and endothelial function. ${ }^{14}$ With an incidence of $25 \%$ in adults, ATC has been associated with increased transfusion requirements, a greater incidence of organ dysfunction, a longer intensive care unit and overall hospital stay, and a fourfold increase in mortality in the adult population. ${ }^{11-13} 1516$

There are a handful of retrospective studies describing ATC in the pediatric population. ${ }^{17-21}$ While all have identified the presence of pediatric ATC, the incidence varies widely between studies $(8.4 \%-57 \%) .{ }^{17-21}$ In addition, all of these prior studies have found an association between pediatric ATC and mortality (OR 2.2 to 4.2). However, none have quantified the impact of ATC on multiple organ dysfunction syndrome (MODS). In pediatric populations, MODS is associated with an increased risk of mortality as well as short-term morbidity and serves as a validated proxy for poor outcomes when mortality rates may be too low to quantify the full effect of a clinical condition. ${ }^{22}$ Because MODS has not been evaluated in pediatric ATC, the true impact of pediatric ATC may be significantly 
under-represented by prior studies focused on mortality. Given the significance of trauma in the pediatric population and this important limitation in prior pediatric ATC studies, the objective of this work is to describe the incidence and outcomes in pediatric ATC with specific focus on the relationship between pediatric ATC and MODS.

\section{METHODS}

\section{Study population}

All patients with trauma presenting to the University of California, Benioff Children's Hospital Oakland (BCHO) between 2006 and 2015 were retrospectively identified through the $\mathrm{BCHO}$ trauma registry. $\mathrm{BCHO}$ is a Level 1 pediatric trauma center in an urban area with approximately 800 trauma team activations each year. The BCHO trauma registry is a prospectively gathered comprehensive and consecutive list detailing all patients with an admitting diagnosis of trauma at $\mathrm{BCHO}$. Once identified, inclusion and exclusion criteria as well as demographic information was verified in the entire cohort using the BCHO electronic health record. For patients that met criteria for inclusion and analysis, demographics, specifics of the trauma, significant events in the associated hospital course, and outcomes were extracted from the registry. Additional laboratory and outcome data along with missing data from the registry were retrospectively obtained from the $\mathrm{BCHO}$ electronic health record in the analyzed cohort. This study protocol was approved by the $\mathrm{BCHO}$ institutional review board.

Only patients with trauma and coagulation laboratories drawn at their presentation to the emergency room were included in the study. At $\mathrm{BCHO}$ during this study period, the decision to send coagulation studies was based on physician preference. Patients were excluded if they (1) were $>18$ years of age, (2) were admitted with a non-mechanical mechanism of injury, specifically drowning, hanging, or burns, as these mechanisms may result in a different biologic response than mechanical trauma, (3) were on anticoagulation medications prior to injury, (4) had coagulation testing $>4$ hours after the time of injury, and (5) received fresh frozen plasma prior to their laboratory draw.

\section{Study variables}

The presence of ATC was the primary predictor variable and was defined as an international normalized ratio (INR) $\geq 1.3$. This was selected as the predictor variable based on the use of INR as a definition of ATC in prior studies. ${ }^{17-21}$ In the sub-analysis of mortality and organ dysfunction, ATC was defined as either an INR $\geq 1.3$, a partial thromboplastin time (PTT) $\geq 35 \mathrm{~s}$, or both. While definitions of ATC have varied in the literature, both cutoffs have been used in previous studies. ${ }^{18} 192324$

The primary outcome was development of new or progressive MODS. New or progressive MODS was defined by Proulx et al as new organ dysfunction of two or more organ systems or progressive organ dysfunction of one organ system in addition to one already dysfunctional organ system. ${ }^{22} 2526$ To make this diagnosis, dysfunction of the cardiovascular, respiratory, neurologic, renal, hepatic, and gastrointestinal organ systems was determined for each of the 6 days following day 1 of trauma. ${ }^{25} 26$ (table 1). For the purposes of this study, hematologic dysfunction was excluded from the MODS diagnostic criteria to capture organ dysfunction without confounding from the predictor variable. Secondary outcomes were in-hospital mortality, duration of hospitalization in survivors excluding in-patient rehabilitation, pediatric intensive care unit (PICU)-free days at day 28, mechanical ventilator-free days at day 28 , readmission within

\begin{tabular}{|c|c|}
\hline Organ system & Criteria for dysfunction \\
\hline Cardiovascular & $\begin{array}{l}\text { Hypotension } \\
\text { - Systolic BP }<40 \mathrm{~mm} \mathrm{Hg} \text { for patients younger than } 12 \\
\text { months } \\
\text { - Systolic BP }<50 \mathrm{~mm} \mathrm{Hg} \text { for patients } 12 \text { months or older } \\
\text { Bradycardia or tachycardia } \\
\text { - Heart rate }<50 \text { or }>220 \text { beats/min in patients younger } \\
\text { than } 12 \text { months } \\
\text { - Heart rate }<40 \text { or }>200 \text { beats/min in patients } 12 \text { months } \\
\quad \text { or older } \\
\text { Cardiac arrest } \\
\text { Serum } \mathrm{pH}<7.2 \text { with normal arterial carbon dioxide level } \\
\text { Continuous IV infusion of inotropic agents to maintain BP } \\
\text { and/or cardiac output }\end{array}$ \\
\hline Respiratory & $\begin{array}{l}\text { Tachypnea } \\
\text { - Respiratory rate }>90 \text { breaths/min for patients younger } \\
\text { than } 12 \text { months } \\
\text { - Respiratory rate }>70 \text { breaths/min for patients } 12 \\
\text { months or older } \\
-\mathrm{PaCO}_{2} \text { of }>65 \mathrm{~mm} \mathrm{Hg} \\
\mathrm{PaO}_{2} \text { of }<40 \mathrm{~mm} \mathrm{Hg} \\
\text { Ratio of } \mathrm{PaO} \mathrm{O}_{2} \text { to fraction of inspired oxygen }<200 \text { in the } \\
\text { absence of cyanotic congenital heart disease }\end{array}$ \\
\hline Neurologic & $\begin{array}{l}\text { Glasgow Coma Score }<5 \\
\text { Fixed dilated pupils }\end{array}$ \\
\hline Renal & $\begin{array}{l}\text { Serum blood urea nitrogen } \geq 100 \mathrm{mg} / \mathrm{dL} \\
\text { Serum creatinine } \geq 2 \mathrm{mg} / \mathrm{dL} \\
\text { Dialysis or hemofiltration }\end{array}$ \\
\hline Hepatic & - Total bilirubin level $>3 \mathrm{mg} / \mathrm{dL}$ \\
\hline Gastrointestinal & $\begin{array}{l}\text { Evidence of gastroduodenal bleeding resulting in (1) a } \\
\text { drop in hemoglobin of } \geq 2 \mathrm{~g} / \mathrm{dL} \text { over } 24 \text { hours, (2) blood } \\
\text { transfusion, or (3) hypotension with BP less than third } \\
\text { percentile for age }\end{array}$ \\
\hline
\end{tabular}

MODS was defined as new organ dysfunction of two or more organ systems or progressive organ dysfunction of one organ system in addition to one already dysfunctional organ system determined each of the 6 days following day 1 of trauma. 222526

BP, blood pressure; IV, Intravenous; MODS, multiple organ dysfunction syndrome; $\mathrm{PaCO2}$, Partial pressure of arterial carbon dioxide; $\mathrm{PaO2}$, Partial pressure of arterial oxygen.

30 days after discharge, and development of pediatric acute respiratory distress syndrome (PARDS). PARDS was defined by the Pediatric Acute Lung Injury Consensus Conference definition as (1) acute onset within 7 days of trauma, (2) hypoxia demonstrated by either a partial pressure of oxygen in arterial blood $(\mathrm{PaO} 2)$ to fraction of inspired oxygen $(\mathrm{P} / \mathrm{F})$ ratio $<300$ or an oxygenation index $>4$, (3) chest imaging showing a new pulmonary infiltrate consistent with parenchymal disease, and (4) respiratory findings not explained by cardiac failure or fluid overload. ${ }^{27}$

Additional information including demographics, trauma mechanism, and medical interventions were also collected. Injury severity was assessed by the Injury Severity Score (ISS) which was considered as a continuous scale and categorized into mild (0-14), moderate (15-29), and severe (30-75) trauma. ${ }^{28-30}$ Arterial hypotension was defined as a systolic blood pressure of $<60 \mathrm{~mm} \mathrm{Hg}$ in neonates 0 to 30 days old, $<70 \mathrm{~mm} \mathrm{Hg}$ in infants 30 days to 1 year old, $<70 \mathrm{~mm} \mathrm{Hg}+$ (age in years $\mathrm{x}$ 2) $\mathrm{mm} \mathrm{Hg}$ in children 1 year to 10 years old, and $<90 \mathrm{~mm}$ $\mathrm{Hg}$ in children and adolescents $>10$ years old based on reference points established in the Pediatric Advanced Life Support guidelines. ${ }^{31}$ 


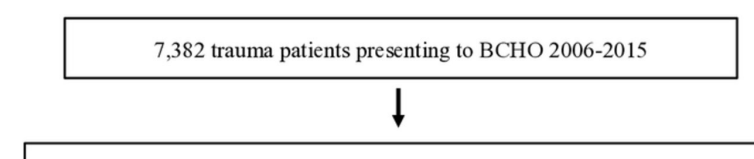

652 patients with coagulation tests drawn at presentation
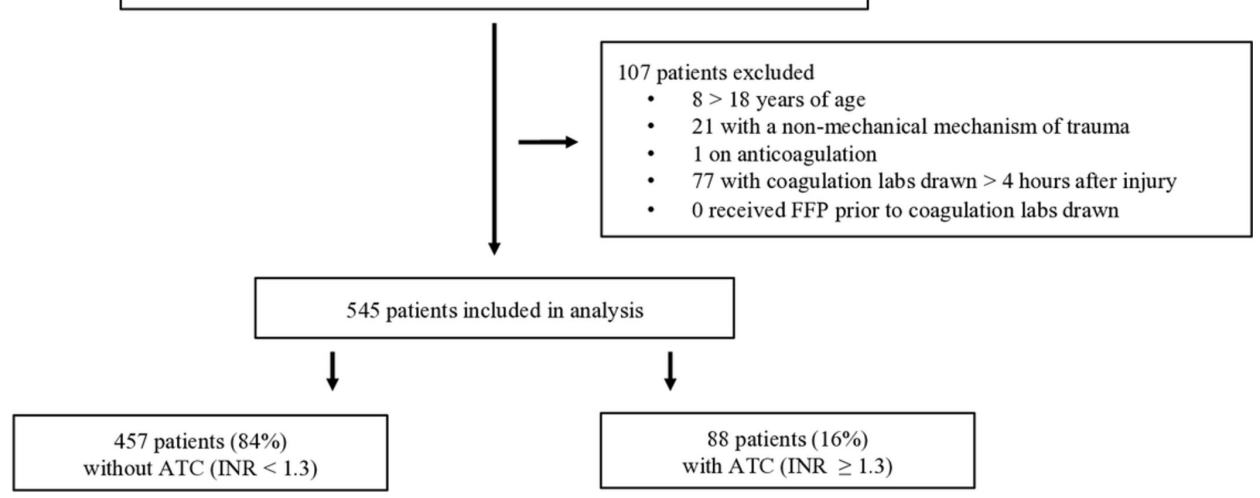

Figure 1 CONSORT diagram of patients reviewed, included, and excluded. ATC, acute traumatic coagulopathy; BCHO, Benioff Children's Hospital Oakland; CONSORT, CONsolidated Standards Of Reporting Trials; FFP, fresh frozen plasma; INR, international normalized ratio.

\section{Statistical analysis}

Univariate and bivariate analyses were performed to evaluate patient demographics, specifics of injury, new or progressive MODS, mortality, and morbidity. Proportions of dichotomous data and medians of non-parametric continuous data were calculated with $95 \%$ CIs and p values. An $\alpha$ of 0.05 was preset as the cut-off for statistical significance. The $\chi^{2}$ test was used to compare proportions and categorical variables whereas the Mann-Whitney U test was used for comparison of continuous non-parametric data. Multivariable logistic regression was performed to assess ATC as an independent predictor of both new or progressive MODS and in-hospital mortality. Logistic regression was conducted in a stepwise way with inclusion of predictors based on biologic plausibility and/or a $p$ value $<0.1$ when included in the model. The number of variables was limited due to the number of outcomes available for the analysis. Ultimately, age, sex, presence of arterial hypotension, and ISS were included as covariates in the regression model. All analyses were performed using Stata/SE, V.14.1.32

\section{RESULTS}

A total of 7382 pediatric patients with trauma presented to BCHO between 2006 and 2015 (figure 1). Of those, 652 patients had coagulation tests drawn on presentation to the emergency department. In all, 107 patients met exclusion criteria which left 545 patients included in the final analysis. Based on the definition of ATC as an INR $\geq 1.3$ on the initial laboratory draw and within 4 hours of the traumatic injury, 88 patients or $16 \%$ presented with ATC.

Demographics and trauma specifics were gathered on the full 7382 pediatric patients with trauma and there was no significant difference in age, sex, race, ethnicity, or trauma mechanism between those included and excluded in the final analysis (data not shown). In the 545 patients included in the study, there was a higher proportion of Black or African American patients in the ATC group than in the group without ATC $(27.3 \%$ compared with $17.5 \%, p=0.03$, table 2 ). Otherwise, there was no difference in demographics between the two groups. Patients with ATC were less likely to have blunt trauma (83\% compared with $92.6 \%, p=0.04$ ) while a higher but not statistically significant percentage of patients with ATC had penetrating trauma $(p=0.19)$. Among those that had blunt trauma, patients with non-accidental trauma were also more likely to present ATC (21.6\% compared with $10.3 \%, p=0.003)$. In addition, there were also significantly more patients with an unknown trauma mechanism in the group with ATC $(5.7 \%$ compared with $0.2 \%$, $\mathrm{p}<0.001$ ), meaning the mechanism was not clearly described as blunt or penetrating in the $\mathrm{BCHO}$ trauma registry or the electronic medical record.

\begin{tabular}{|c|c|c|c|c|}
\hline & & ATC $(n=88)$ & No ATC $(n=457)$ & $P$ value \\
\hline \multirow[t]{6}{*}{ Age } & $\begin{array}{l}\text { Median age } \\
\text { (range) }\end{array}$ & $7 y(30 d-16 y)$ & $7 y(5 d-17 y)$ & 0.7 \\
\hline & Newborn, n (\%) & $2(2.3)$ & $17(3.7)$ & 0.5 \\
\hline & Infant, n (\%) & $13(14.8)$ & $56(12.3)$ & 0.52 \\
\hline & Toddler, n (\%) & $12(13.6)$ & $55(12)$ & 0.68 \\
\hline & Child, $\mathrm{n}(\%)$ & $39(44.3)$ & $201(44)$ & 0.95 \\
\hline & Adolescent, n (\%) & $22(25)$ & $128(28)$ & 0.56 \\
\hline Sex & Female, n (\%) & $33(38)$ & $152(33.3)$ & 0.96 \\
\hline \multirow[t]{6}{*}{ Race } & $\begin{array}{l}\text { American Indian } \\
\text { or Alaskan Native, } \\
\mathrm{n}(\%)\end{array}$ & $1(1.1)$ & $2(0.4)$ & 0.42 \\
\hline & Asian, n (\%) & $6(6.8)$ & $32(7)$ & 0.95 \\
\hline & $\begin{array}{l}\text { Black or African } \\
\text { American, } \mathrm{n}(\%)\end{array}$ & $24(27.3)$ & $80(17.5)$ & 0.03 \\
\hline & $\begin{array}{l}\text { Native Hawaiian } \\
\text { or Pacific Islander, } \\
\mathrm{n}(\%)\end{array}$ & $0(0)$ & $2(0.4)$ & 0.53 \\
\hline & White, n (\%) & $50(56.8)$ & $285(62.4)$ & 0.33 \\
\hline & Other, n (\%) & $7(8)$ & $56(12.3)$ & 0.25 \\
\hline Ethnicity & Hispanic, n (\%) & $19(21.6)$ & $127(27.8)$ & 0.23 \\
\hline \multirow{3}{*}{$\begin{array}{l}\text { Trauma } \\
\text { mechanism }\end{array}$} & Blunt, n (\%) & $73(83)$ & $423(92.6)$ & 0.04 \\
\hline & Penetrating, $n(\%)$ & $10(11.3)$ & $33(7.2)$ & 0.19 \\
\hline & Unknown, n (\%) & $5(5.7)$ & $1(0.2)$ & $<0.001$ \\
\hline ISS & Median ISS (range) & $25(0-75)$ & $9(0-38)$ & $<0.001$ \\
\hline \multirow{2}{*}{\multicolumn{5}{|c|}{$\begin{array}{l}\text { ATC is defined as an international normalized ratio } \geq 1.3 \text {. For breakdown by age newborns } \\
\text { were } 0 \text { to } 30 \text { days old, infants were } 31 \text { to } 364 \text { days old, toddlers were } 1 \text { to } 3 \text { years old, } \\
\text { children were } 4 \text { to } 11 \text { years old and adolescents were } 12 \text { to } 18 \text { years old. } \\
\text { ATC, acute traumatic coagulopathy; ISS, Injury Severity Score. }\end{array}$}} \\
\hline & & & & \\
\hline & & & & \\
\hline
\end{tabular}




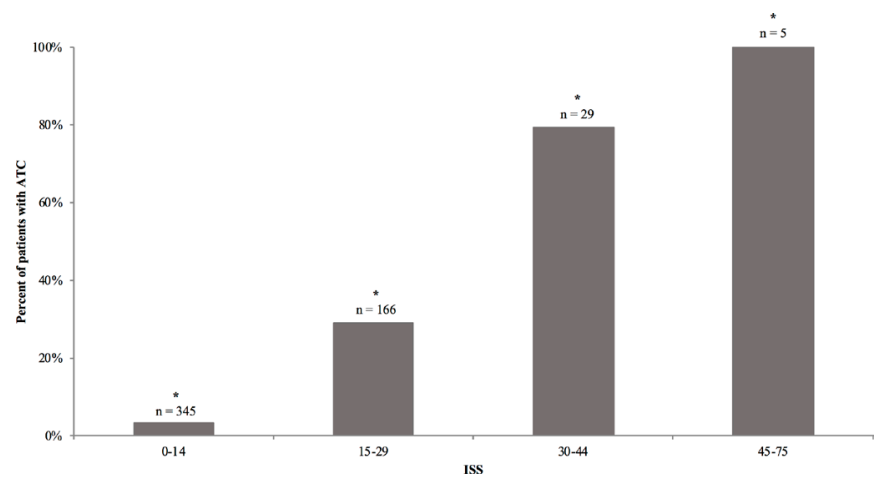

Figure 2 Percent of patients with ATC at each ISS category. * indicates $p<0.001$. ATC, acute traumatic coagulopathy; ISS, Injury Severity Score.

The median ISS for all patients presenting between 2006 and 2015 was 4, whereas the median for the analyzed cohort was 12. Patients with ATC had a higher median ISS (25 compared with $9, \mathrm{p}<0.001$ ) and encompassed the full range of possible ISS values (table 2). Lower ISS categories were assigned to the majority of patients in the full cohort. With increasing ISS, the percent of patients with ATC increased (figure 2). In the highest ISS category which contained only five patients, all patients had ATC.

The overall development of new or progressive MODS in the full cohort was 16.9\% (92 patients) and patients with ATC were more likely to develop MODS than those without ATC (68.4\% compared with $7.7 \%, \mathrm{p}<0.001$ (table 3 )). The overall mortality of patients presenting between 2006 and 2015 was 1.1\% (81 patients) and of the analyzed cohort was $4.6 \%$ (25 patients). The mortality in patients with ATC was $26.1 \%$ (23 patients) and was significantly greater than the mortality of $0.4 \%$ (2 patients) in patients without ATC $(\mathrm{p}<0.001)$. Patients with ATC were also more likely to develop PARDS, had a longer duration of hospitalization in survivors, had fewer PICU-free days at day 28 , and had fewer mechanical ventilation-free days at day 28 than those without ATC.

New or progressive MODS in patients with an elevated INR was significantly greater than in those with a normal INR and did not vary in those with normal or elevated PTT (table 4). In patients with a normal INR, there was no difference between in-hospital mortality in patients with normal compared with an
Table 4 Mortality and new or progressive MODS in patients with ATC defined by an INR $\geq 1.3$, PTT $\geq 35 \mathrm{~s}$, or both

\begin{tabular}{llll}
\hline & $\begin{array}{l}\text { PTT }<35 \mathrm{~s} \\
\%(95 \% \mathrm{Cl})\end{array}$ & $\begin{array}{l}\text { PTT } \geq 35 \mathrm{~s} \\
\%(95 \% \mathrm{Cl})\end{array}$ & P value \\
\hline $\begin{array}{l}\text { Development of new or } \\
\text { progressive MODS }\end{array}$ & & & \\
$\quad$ INR $<1.3$ & $7.3(4.8$ to 9.9$)$ & $9.8(2.4$ to 17.3$)$ & 0.49 \\
INR $\geq 1.3$ & $64.1(49$ to 79.2$)$ & $65.3(52$ to 78.6$)$ & 0.91 \\
$\quad$ p value & $<0.001$ & $<0.001$ & \\
$\begin{array}{l}\text { In-hospital mortality } \\
\text { INR }<1.3\end{array}$ & $0.3(0.2$ to 0.7$)$ & $1.6(1.5$ to 4.8$)$ & 0.13 \\
INR $\geq 1.3$ & $15.4(4.1$ to 26.7$)$ & $34.7(21.4$ to 48$)$ & 0.04 \\
\hline p value & $<0.001$ & $<0.001$ & \\
\hline
\end{tabular}

ATC, acute traumatic coagulopathy; $\mathrm{Cl}$, confidence interval; INR, international normalized ratio; MODS, multiple organ dysfunction syndrome; PTT, partial thromboplastin time.

elevated PTT. However, patients with an elevated INR had a higher mortality with the highest in-hospital mortality seen in those with an elevated INR and PTT. Of note, there was no difference in injury severity between these two groups.

On multivariable logistic regression, the presence of ATC was found to be an independent predictor of both new or progressive MODS and in-hospital mortality (table 5). Arterial hypotension and an ISS of $\geq 30$ were also found to be independent predictors for both outcomes.

\section{DISCUSSION}

We present here an examination of the incidence, modifiers, and associated outcomes of ATC in a pediatric population. In this large pediatric trauma cohort, ATC was present in $16 \%$ of included pediatric patients with trauma, was associated with worse injury, and was an independent predictor of in-hospital mortality. The consistency of this result with prior studies across different hospital settings and communities further confirms ATC as a significant entity across the pediatric trauma population. ${ }^{17-21}$ Furthermore, ATC was an independent predictor of new or progressive MODS. This newly described relationship between ATC and MODS suggests the associated outcomes in ATC are more far reaching than previously described by mortality alone.

Table 3 Mortality and morbidity in patients with and without ATC defined by an INR $\geq 1.3$.

\begin{tabular}{|c|c|c|c|}
\hline & ATC $(n=88)$ & No ATC $(n=457)$ & \\
\hline Complication and event outcomes & $\%(95 \% \mathrm{Cl})$ & $\%(95 \% \mathrm{Cl})$ & $\mathrm{p}$ value \\
\hline Development of new or progressive MODS & 64.8 (54.8 to 74.8$)$ & $7.7(5.2$ to 10.1$)$ & $<0.001$ \\
\hline In-hospital mortality & 26.1 (17.6 to 36.5$)$ & $0.4(0$ to 1$)$ & $<0.001$ \\
\hline Developed of PARDS & $35.2(25.1$ to 45.5$)$ & 3.5 (1.8 to 5.2$)$ & $<0.001$ \\
\hline Readmission within 30 days of discharge & $1.2(1.1$ to 3.5$)$ & 1.3 (0.3 to 2.4$)$ & 0.92 \\
\hline Duration outcomes & Median days (IQR) & Median days (IQR) & $\mathrm{p}$ value \\
\hline Duration of hospitalization in survivors & $10(7.7$ to 12.3$)$ & 3 (2.8 to 3.2$)$ & $<0.001$ \\
\hline PICU-free days at day 28 & 17 (0 to 23$)$ & $26(25$ to 28$)$ & $<0.001$ \\
\hline Mechanical ventilator-free days at day 28 & 21 (0 to 27$)$ & 28 (28 to 28$)$ & $<0.001$ \\
\hline
\end{tabular}

New or progressive MODS was defined by the Proulx et al criteria and excludes hematologic dysfunction.22 2526 PARDS was defined by the pediatric acute lung injury consensus conference definition. ${ }^{27}$ The total number of survivors in patients with ATC and without ATC was 63 and 455 , respectively. Those that died were considered to have 0 PICU-free days and 0 mechanical ventilator-free days at day 28.

ATC, acute traumatic coagulopathy; INR, international normalized ratio; IQR, interquartile range; MODS, multiple organ dysfunction syndrome; PARDS, pediatric acute respiratory distress syndrome; PICU, pediatric intensive care unit 


\begin{tabular}{|c|c|c|c|}
\hline & OR & $95 \% \mathrm{Cl}$ & $P$ value \\
\hline \multicolumn{4}{|c|}{ Development of new or progressive MODS } \\
\hline ATC & 2.7 & 2.1 to 3.4 & $<0.001$ \\
\hline Arterial hypotension & 3.1 & 1.4 to 7.1 & 0.007 \\
\hline$I S S \geq 30$ & 4.6 & 1.8 to 11.5 & 0.001 \\
\hline \multicolumn{4}{|l|}{ In-hospital mortality } \\
\hline ATC & 4.2 & 2.4 to 7.2 & $<0.001$ \\
\hline Arterial hypotension & 5.4 & 1.8 to 16.2 & 0.003 \\
\hline$I S S \geq 30$ & 4.9 & 1.7 to 14.3 & 0.004 \\
\hline
\end{tabular}

ATC is defined by an INR $\geq 1.3$

ATC, acute traumatic coagulopathy; $\mathrm{Cl}$, confidence interval; INR, international normalized ratio; ISS, injury severity score; MODS, multiple organ dysfunction syndrome; $\mathrm{OR}$, odds ratio.

Another important set of findings in this study is the breakdown of organ dysfunction and mortality association by measure of coagulopathy. First and unsurprisingly, organ dysfunction and mortality were the highest in patients with elevations of both INR and PTT. This suggests global dysfunction of secondary hemostasis is seen in patients who do worse. Second, there was no statistically significant difference in association with organ dysfunction or mortality in those with an isolated elevated PTT compared with those with no coagulopathy. Third, an isolated INR coagulopathy was associated with an increase in both organ dysfunction and mortality from baseline and, in the case of organ dysfunction, carried the same association as a combined coagulopathy. Put another way, PTT seems to contribute to mortality but not to organ dysfunction. This result can be contrasted with a recent adult study which showed the highest mortality in patients with a combined INR and PTT coagulopathy but a higher mortality in an isolated PTT coagulopathy as compared with an isolated INR coagulopathy. ${ }^{33}$

It is unclear why this particular pattern is seen in the pediatric population. It may suggest that the extrinsic pathway as measured by INR is an important driver of organ dysfunction and mortality in pediatric ATC. Components of the coagulation system including Factors VII and X, which are important in the extrinsic pathway, do not develop fully until late childhood or early adolescence. ${ }^{34} 35$ This lack of reserve may impact both organ dysfunction and mortality whereas factors in the intrinsic pathway may be more robust. Complicating this further, though the incidence of ATC is similar in adult and pediatric populations, children are much less likely to bleed in the presence of this coagulopathy than their adult counterparts. Therefore, the differences in INR and PTT may be more reflective of global hemostatic and endothelial dysfunction. Taken together, there may be key biologic differences in the development of ATC between children and adults even though the end result of poor outcomes is similar and these biologic differences require further mechanistic investigation in future studies.

Another interesting result that warrants future study and may help elucidate the underlying mechanism of ATC is the small population with low ISS $(<15)$ but with the presence of ATC. Though a small group of only 10 patients, 4 of these patients presented with penetrating injuries which is a much higher percentage than was seen in the total cohort and in those with ATC. This suggests there may be something unique about the mechanism of penetrating trauma that may be more likely to drive ATC. Further mechanistic study should focus on this subset of patients as potentially key in contributing mechanisms.
The strengths of this study include the relatively large sample size, the use of prospectively gathered data, and the consideration of organ dysfunction in addition to mortality as a meaningful outcome. There are several important limitations to this study. Specifically, though the BCHO trauma registry contains prospectively gathered data, these data were verified and supplemented through retrospective analysis and therefore carry limitations in data accuracy and control over measured variables. For example, the patients included in this study were only those with laboratory samples drawn at the time of admission. The results are not truly representative of all patients with trauma, but instead likely represent the sickest patients at the time of presentation. In addition, the BCHO trauma database is limited in the type of data it includes, particularly fluid and blood product administration as it relates to the timing of laboratory collection. Because the time to presentation to $\mathrm{BCHO}$ tended to be short and blood draws were done as close to the time of presentation as possible, it is reasonable that this effect is small but still deserves more careful consideration in future prospective work. Finally, as is true in many pediatric studies, there were a relatively small number of outcomes particularly mortality. This limited the number of covariates that could be included in the logistic regression analysis and may result in an estimate of effect with some residual confounding.

In summary, ATC is present following pediatric trauma and is associated with organ dysfunction, mortality, and other morbidities. ATC along with arterial hypotension and high injury severity are all independent predictors of mortality and organ dysfunction. Pediatric ATC may be biologically distinct from adult ATC and further prospective mechanistic studies are needed to characterize pediatric ATC and identify key pathways in this process.

Contributors All authors participated in the study design, statistical analysis, interpretation of results, and manuscript preparation. Dr Nair wrote the IRB proposal, participated in the IRB review, performed the data extraction, and conducted the data cleaning.

Funding ABN's 4th year fellowship salary was provided through a T32 grant (T32 HD 49303-10) which provided protect research time for the completion of this study. This study was otherwise not supported by any external funding.

Competing interests None declared.

Patient consent for publication Not required.

Ethics approval Benioff Children's Hospital Oakland, Institutional Review Board, Exempt.

Provenance and peer review Not commissioned; externally peer reviewed. Data availability statement Data are available upon reasonable request.

Open access This is an open access article distributed in accordance with the Creative Commons Attribution Non Commercial (CC BY-NC 4.0) license, which permits others to distribute, remix, adapt, build upon this work non-commercially, and license their derivative works on different terms, provided the original work is properly cited, appropriate credit is given, any changes made indicated, and the use is non-commercial. See: http://creativecommons.org/licenses/by-nc/4.0/.

\section{REFERENCES}

1 Centers for Disease Control and Prevention, Health, United States, Injury,. Table 75. Initial injury-related visits to hospital emergency departments, by sex, age, and intent and mechanism of injury: United States, average annual, selected years 2005-2006 through 2010-2011. 2015. www.cdc.gov/nchs/hus/injury.htm (Accessed 16 Jun 2019).

2 Centers for Disease Control and Prevention (CDC). Vital signs: Unintentional injury deaths among persons aged 0-19 years - United States, 2000-2009. MMWR Morb Mortal Wkly Rep 2012:61:270-6.

3 National Vital Statistics System. Deaths, percent of total deaths, and death rates for the 15 leading causes of death in 5-year age groups, by race and sex: United States, 1999-2014. https://www.cdc.gov/nchs/nvss/mortality/lcwk1.htm (Accessed 16 Jun, 2019).

4 Osterman MJK, Kochanek KD, MacDorman MF, Strobino DM, Guyer B. Annual summary of vital statistics: 2012-2013. Pediatrics 2015;135:1115-25. 
5 Valadka S, Poenaru D, Dueck A. Long-term disability after trauma in children. J Pediatr Surg 2000;35:684-7

6 Wesson DE, Williams J, Spence LJ, Filler RM, Armstrong PF, Pearl RH. Functional outcome in pediatric trauma. J Trauma 1989;29:589-92.

7 Ardolino A, Sleat G, Willett K. Outcome measurements in major trauma--results of a consensus meeting. Injury 2012;43:1662-6.

8 Miller TR, Romano EO, Spicer RS. The cost of childhood unintentional injuries and the value of prevention. Future Child 2000;10:137-63.

9 Sharar SR. The ongoing and worldwide challenge of pediatric trauma. Int J Crit IIIn Inj Sci 2012:2:111-3.

10 Finklestein EA, Corso PS, Miller TR. Incidence and economic burden of injuries in the United States. Oxford, United Kingdom: Oxford University Press, 2006.

11 Brohi K, Cohen MJ, Davenport RA. Acute coagulopathy of trauma: mechanism, identification and effect. Curr Opin Crit Care 2007;13:680-5.

12 Brohi K, Singh J, Heron M, Coats T. Acute traumatic coagulopathy. J Trauma 2003; 54:1127-30.

13 Cohen MJ, West M. Acute traumatic coagulopathy: from endogenous acute coagulopathy to systemic acquired coagulopathy and back. J Trauma 2011;70:\$47-9.

14 White NJ, Ward KR, Pati S, Strandenes G, Cap AP. Hemorrhagic blood failure: oxygen debt, coagulopathy, and endothelial damage. J Trauma Acute Care Surg 2017;82:S41-9.

15 Cohen MJ, Kutcher M, Redick B, Nelson M, Call M, Knudson MM, Schreiber MA, Bulger EM, Muskat P, Alarcon LH, et al. Clinical and mechanistic drivers of acute traumatic coagulopathy. J Trauma Acute Care Surg 2013;75:S40-7.

16 Cohen MJ. Acute traumatic coagulopathy: clinical characterization and mechanistic investigation. Thromb Res 2014:133 Suppl 1:S25-7.

17 Patregnani JT, Borgman MA, Maegele M, Wade CE, Blackbourne LH, Spinella PC. Coagulopathy and shock on admission is associated with mortality for children with traumatic injuries at combat support hospitals. Pediatr Crit Care Med 2012;13:273-7.

18 Whittaker B, Christiaans SC, Altice JL, Chen MK, Bartolucci AA, Morgan CJ, Kerby JD, Pittet J-F. Early coagulopathy is an independent predictor of mortality in children after severe trauma. Shock 2013;39:421-6.

19 Leeper CM, Kutcher M, Nasr I, McKenna C, Billiar T, Neal M, Sperry J, Gaines BA. Acute traumatic coagulopathy in a critically injured pediatric population: definition, trend over time, and outcomes. J Trauma Acute Care Surg 2016;81:34-41.

20 Strumwasser A, Speer AL, Inaba K, Branco BC, Upperman JS, Ford HR, Lam L, Talving P, Shulman I, Demetriades $\mathrm{D}$. The impact of acute coagulopathy on mortality in pediatric trauma patients. J Trauma Acute Care Surg 2016;81:312-8.

21 Liras IN, Caplan HW, Stensballe J, Wade CE, Cox CS, Cotton BA. Prevalence and impact of admission acute traumatic coagulopathy on treatment intensity, resource use, and mortality: an evaluation of 956 severely injured children and adolescents. J Am Coll Surg 2017;224:625-32.
22 Watson RS, Crow SS, Hartman ME, Lacroix J, Odetola FO. Epidemiology and outcomes of pediatric multiple organ dysfunction syndrome. Pediatr Crit Care Med 2017; 18:\$4-16.

23 Frith D, Goslings JC, Gaarder C, Maegele M, Cohen MJ, Allard S, Johansson PI, Stanworth S, Thiemermann C, Brohi K. Definition and drivers of acute traumatic coagulopathy: clinical and experimental investigations. J Thromb Haemost 2010;8:1919-25.

24 Christie SA, Kornblith LZ, Howard BM, Conroy AS, Kunitake RC, Nelson MF, Hendrickson CM, Calfee CS, Callcut RA, Cohen MJ. Characterization of distinct coagulopathic phenotypes in injury: pathway-specific drivers and implications for individualized treatment. J Trauma Acute Care Surg 2017;82:1055-62.

25 Proulx F, Fayon M, Farrell CA, Lacroix J, Gauthier M. Epidemiology of sepsis and multiple organ dysfunction syndrome in children. Chest 1996;109:1033-7.

26 Lin JC, Spinella PC, Fitzgerald JC, Tucci M, Bush JL, Nadkarni VM, Thomas NJ, Weiss SL, Prevalence S. Sepsis Prevalence, Outcomes, and Therapy Study Investigators. New or progressive multiple organ dysfunction syndrome in pediatric severe sepsis: a sepsis phenotype with higher morbidity and mortality. Pediatr Crit Care Med 2017:18:8-16

27 Khemani RG, Smith LS, Zimmerman JJ, Erickson S. Pediatric Acute Lung Injury Consensus Conference Group. Pediatric acute respiratory distress syndrome: definition, incidence, and epidemiology: proceedings from the pediatric acute lung injury consensus conference. Pediatr Crit Care Med 2015;16:S23-40.

28 Baker SP, O'Neill B, Haddon W, Long WB. The injury severity score: a method for describing patients with multiple injuries and evaluating emergency care. J Trauma 1974; 14:187-96

29 Copes WS, Champion HR, Sacco WJ, Lawnick MM, Keast SL, Bain LW. The injury severity score revisited. J Trauma 1988;28:69-77

30 Brown JB, Gestring ML, Leeper CM, Sperry JL, Peitzman AB, Billiar TR, Gaines BA. The value of the injury severity score in pediatric trauma: time for a new definition of severe injury? J Trauma Acute Care Surg 2017;82:995-1001.

31 Pediatric Advanced Life Support. American Heart Association guidelines for cardiopulmonary resuscitation and emergency cardiovascular care. 2017. https:// eccguidelines.heart.org/ (Accessed 16 Jun 2019).

32 StataCorp. Stata statistical software: release 14. College Station, TX: StataCorp LP, 2015.

33 Kunitake RC, Howard BM, Kornblith LZ, Christie SA, Conroy AS, Cohen MJ, Callcut RA. Individual clotting factor contributions to mortality following trauma. J Trauma Acute Care Surg $2017 ;$;82:302-8. Fb.

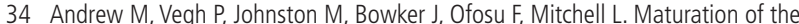
hemostatic system during childhood. Blood 1992;80:1998-2005.

35 Ignjatovic V, Mertyn E, Monagle P. The coagulation system in children: developmental and pathophysiological considerations. Semin Thromb Hemost 2011;37:723-9. 